\title{
Editorial: What's Love Got to Do With It: The Evolution of Monogamy
}

\author{
Nancy G. Solomon ${ }^{1 *}$ and Alexander G. Ophir ${ }^{2}$ \\ ${ }^{1}$ Department of Biology, Miami University, Oxford, OH, United States, ${ }^{2}$ Department of Psychology, Cornell University, Ithaca, \\ NY, United States
}

Keywords: social monogamy, genetic monogamy, infidelity, biparental care, spatio-temporal relationship, pair bond

\section{Editorial on the Research Topic}

\section{What's Love Got to Do With It: The Evolution of Monogamy}

Monogamy and pair-bonding are central to the human experience in the majority of cultures worldwide (Schacht and Kramer), which might explain the long-running fascination scientists have for understanding monogamy within mammals and across other taxa. The inherent interest in monogamy in western cultures, in part, may be a result of anthropomorphism and a belief that who we mate with defines us. Nevertheless, monogamy captivates the human mind and has been the subject matter in art, religion and literature for centuries. It is a topic that has brought together researchers from diverse backgrounds including anthropology, behavioral ecology, psychology, psychiatry, pediatrics, neurobiology, endocrinology, and molecular biology.

There is still much we do not understand about monogamy. A collective, systematic, and concerted effort toward answering questions surrounding the meaning of monogamy is overdue. This Research Topic aimed to bring experts, from a variety of disciplines and conceptual approaches, together to showcase our current understanding of monogamy. This issue is composed

\section{OPEN ACCESS}

Edited and reviewed by:

Elise Huchard

UMR5554 Institut des Sciences de l'Evolution de Montpellier (ISEM), France

*Correspondence:

Nancy G. Solomon solomong@muohio.edu

Specialty section:

This article was submitted to Behavioral and Evolutionary Ecology,

a section of the journal

Frontiers in Ecology and Evolution

Received: 18 March 2020 Accepted: 03 April 2020 Published: 28 April 2020 of articles focusing on the specific and general aspects of monogamy within a variety of species, and taking empirical, methodological, conceptual, or theoretical approaches to provide a deeper and more complete understanding of aspects of behavior that comprise monogamy, its evolution, and its meaning.

The term "monogamy" can be used in very different contexts or ways, emphasizing the need to carefully delineate or define terminology. This is a critical concern because not only can there be confusion between different forms of monogamy (e.g., "social" and "genetic" monogamy), but also about the particular behaviors that should be included within the concept of monogamy. Thus, consistent and clearly defined terminology is crucial, especially when conducting comparative analyses (Huck et al.; Kappeler and von Schaik, 2002). Early studies of monogamy often assumed that animals with a high degree of spatio-temporal overlap mated exclusively with each other (Wittenberger and Tilson, 1980). Since the advent of molecular techniques enabling parentage determination, it has become clear that exclusive mating with a social partner (i.e., genetic monogamy) is much rarer than social partnerships in which mating outside the pair occurs (e.g., eastern bluebirds, Silia silis, Gowaty and Karlin, 1984, indigo buntings, Passerina cyanea, Westneat, 1987; fat-tailed dwarf lemur, Cheirogalaus medius, Fietz et al., 2000). Thus, the propensity for two opposite sexed individuals to live together need not relate to an exclusive mating relationship, in itself requiring a reevaluation of the common understanding of monogamy.

Social monogamy can be defined in terms of spatial overlap of one adult male and one adult female that live as a pair. Advances in methods to study such behavior in nature, particularly among cryptic subterranean species (like rodents), provide accurate and more refined determinations of behavior that can significantly improve assessment of the behaviors that define monogamy. For example, Sabol et al. demonstrated that incorporating automated radio frequency identification 
tracking (RFID) and social network analysis can provide new opportunities to measure and operationalize monogamous behavior beyond classic laboratory tests of partner preferences (Williams et al., 1992; Donaldson et al., 2010) and assessment of home ranges and spatial overlap using radiotelemetry in the field (Solomon and Jacquot, 2002; Ophir et al., 2008; Lambert, 2018).

Although the spatio-temporal relationship between mating partners provides one important way to define socially monogamous relationships (Emlen and Oring, 1977; Ophir, 2017), other conceptualizations of monogamy focus more heavily on the suites of behaviors that contribute to delineating this social system. Relying on behavioral characteristics to define monogamy (i.e., social association, formation of an attachment, mating pattern, biparental care of offspring, and selective aggression toward same-sex conspecifics) can lead to different views of monogamy because not all the behaviors that contribute to various conceptualizations of monogamy are consistently found in every socially monogamous species. For example, some of the early reviews of monogamy (Kleiman, 1977; Wittenberger and Tilson, 1980) included biparental care as a key feature of monogamy, but we now know that biparental care is not found in all monogamous animals (Brotherton and Rhodes, 1996; Whiteman and Côté, 2004, Table 2; Lambert et al., this issue Supplementary Data sheet 1). Even when biparental care is common (e.g., in avian monogamy, Mock and Fujioka, 1990), the contributions of parents are not necessarily equal and may not be constant over time. Rogers et al. examines the pattern of biparental care seen across multiple litters and finds that the mother and father appear to compensate for the time spent in parental care by the partner. Similarly, Schacht et al. investigate human paternal investment within a population of Maya living in Mexico in response to changes in socioecological factors. The authors investigate how changes in socioecological factors such as the introduction of mechanized farming, and their potential to provide stability in offspring social environments might compensate for a partner's waning parental effort or create opportunities for increased effort. For instance, mechanized farming among the Maya increases efficiency in providing subsistence, mating partnerships, and bi-parental care.

Another issue that can confound our understanding of monogamy is the acknowledgment that individuals within a population typically described as monogamous vary. Indeed, any mating system is best considered to be a collection of individual reproductive decisions, which are shaped by many internal and external factors. For example, many species that are considered monogamous contain individuals that engage in alternative mating tactics. Typically, alternative tactics within mating systems tend to take the form of (socially) monogamous residents that maintain territory, site, or nest fidelity with an opposite-sex partner, or the form of non-monogamous (often promiscuous) wandering or roaming individuals that maintain more than one nest and/or lack the site fidelity of the former. How evolution has maintained the variation in tactics is an important question that strikes at the heart of this phenomenon (Dawkins, 1980; Koprowski, 1993; Taborsky et al., 2008). In this issue, Shuster et al. used data from a 3year study in two geographically separate populations of prairie voles to investigate the average fitness obtained by males and females that exhibited alternative reproductive tactics. They showed that a form of balancing selection could maintain both behavioral phenotypes in the populations. Adopting a socially monogamous resident tactic does not preclude the motivation (or reproductive advantages that presumably support it) to pursue extra-pair matings. So, although the tactics are distinct from each other, an individual can switch from one tactic to another depending on which tactic results in higher fitness under particular environmental conditions. In another paper in this special topic, Rice et al. use optimal performance modeling to predict when it would be better for males that are pair-bonded to stay and guard their mates vs. seek extra-pair copulations in a population where males display alternative mating tactics. The latter would come with the cost of losing matings with their female partner to conspecific males in the population. Together, studies such as these highlight the profound individual variation between and within tactics that exists within "monogamy" and point to external factors (social or ecological) that help shape the evolution of reproductive decision-making.

There are still many unanswered questions that remain about how socially monogamous animals respond to infidelity in their partner. A number of papers in this issue explore different aspects involved in the potential for loss of genetic monogamy in socially monogamous individuals. Pultorak et al. investigates vocalizations among individuals during the formation of a pairbond and during an "infidelity challenge," where the male and female were housed for 1 week with an unfamiliar oppositesex conspecific. Maninger et al. used functional imaging to investigate the changes in cerebral glucose metabolism, and an array of hormones taken from brain and blood after a pairbonded male titi monkey observed his partner in close proximity with a rival male. Maninger et al. provocatively suggest that the experience induced a neural and physiological response indicative of "jealousy" and that such responses preserve pair bonds.

In recent years, a focus on proximate studies like the latter one, and recognition for the tremendous value toward providing a complete understanding of behavior (sensu Tinbergen, 1963), has increased. Studies about the neurogenetic mechanisms underlying characteristics of monogamy, particularly the formation of pair bonds, have received considerable attention (Young and Wang, 2004; Klatt and Goodson, 2013; Fischer et al., 2019) and have been major contributors toward this wave of interest in proximate behavioral mechanisms. Nevertheless, the mechanistic underpinnings of monogamy are complex, and important outstanding questions remain about the relative importance and interrelationship among neurogenetic factors. In a remarkably comprehensive review, Carter and Perkeybile outline many of the behavioral, hormonal, neural and genetic/epigenetic mechanisms that contribute to mating behavior, the formation and maintenance of the pair bond, the emotion humans call "love," and the gulf between them. Similarly, Carp et al. focus on the role of dopamine in the length of time animals have been paired to assess the function of this neurotransmitter in the strength of bonds. Together, these papers provide insight into the deep evolutionary roots of shared 
mechanisms that govern short-term or long-term monogamous relationships, while also demonstrating that there is no one single neurochemical recipe for social monogamy. Finally, ontogenetic effects on monogamy have received comparably little attention compared to Tinbergen's other levels of analysis, though such studies do exist. For example, rodent studies have clearly demonstrated that early-life experience can alter the propensity for monogamy (Bales et al., 2007; Ahern and Young, 2009; Prounis et al., 2015), and the neurochemical substrates that contribute to it (Hiura and Ophir, 2018; Hiura et al., 2018; Kelly et al., 2018; Prounis et al., 2018). Similarly, Al-Naimi et al. examines the effects of social and environmental disruptions in the life of young animals, and discuss how these may affect the tendency of males to behave monogamously.

Many studies of monogamy naturally lead to questions that address the adaptive value of this mating system, but the importance of understanding monogamy from the comparative evolutionary, mechanistic, and developmental perspectives (sensu Tinbergen, 1963) cannot be understated. Questions about the evolution of monogamy have been a steadfast area of interest in behavioral ecology and the study of animal behavior. In the 1980-2000s, the costs and benefits of monogamy to males and females received a lot of attention (Wittenberger and Tilson, 1980; van Schaik and Dunbar, 1990; Hames, 1996; Reavis and Barlow, 1998), and numerous hypotheses were proposed and tested in different species. Since then, great advances in phylogenetic reconstruction have paved the way for a better understanding of the evolution of social monogamy, including the causal factors that led to social monogamy and the factors that were consequences of this social/mating system (Dobson et al., 2010; Lukas and Clutton-Brock, 2013). Previous phylogenetic studies on factors influencing genetic monogamy have not reached consistent conclusions for a number of reasons, including differences and limitations in methodology and the species included in analyses (Clutton-Brock and Isvaran, 2006; Cohas and Allaine, 2009; Huck et al., 2014; Dobson et al., 2018). In this issue, Lambert et al. used phylogenetic corrections to examine factors influencing genetic monogamy within socially monogamous mammals and found that there was not one best model that explained the different ways in which genetic monogamy could be assessed. Numerous life history factors such as pair living and paternal care were important contributors to the top models. These, together with some demographic factors such as density or sex ratio, affected some measures of genetic monogamy. This conclusion is consistent with the argument made by Klug, which considered the lifehistory and ecological conditions that permit the evolution and persistence of monogamy, and advocated for the idea that

\section{REFERENCES}

Ahern, T. H., and Young, L. J. (2009). The impact of early life family structure on adult social attachment, alloparental behavior, and the neuropeptide systems regulating affiliative behaviors in the monogamous prairie vole (Microtus ochrogaster). Front. Behav. Neurosci. 3:2009. doi: 10.3389/neuro.08.017.2009 multiple (interacting) factors influence the display of monogamy. In a more specific example, Macdonald et al., reviewed some of the same functional hypotheses for the evolution and persistence of social and genetic monogamy in wild canids, a mammalian family in which monogamy is common. They proposed the hypothesis that the combination of particular characteristics of canids has led to both monogamy and prosocial cooperation. In another study employing the comparative approach, Kalcounis-Rueppell et al. consider the relationships between the form and function of Peromyscus vocalizations with ecological traits, physiological traits, and different mating systems, ranging from polygyny to monogamy, across seven species of mice.

The study of monogamy has accelerated in the past few decades, painting a nuanced, and at times perplexing yet captivating, picture for what monogamy actually is. Such work has only uncovered more exciting questions that merit investigation, and highlight that we are just beginning to understand what monogamy actually is. Love, for example, isat best-only a small part of this larger phenotypic complex. We hope that the contributed papers contained within this collection will stimulate discussion and promote more research, which in the end, will enhance our understanding of monogamy, and lead to achieving a deeper understating of the mating system often associated with humans and many other species across the animal kingdom.

\section{AUTHOR CONTRIBUTIONS}

AO had the original idea for this topic. AO and NS collaborated on the description and organization of this special topic and wrote this introductory article together.

\section{FUNDING}

Funding from the National Institutes of Health (HD079573), the Army Research Office (65344-LS), and the National Science Foundation (1354760) supported AO during the course of this Research Topic. NS was supported by National Institutes of Health (1R15HD075222-01A1) awarded to NS, Brian Keane and Bruce Cushing (colleagues at Miami University and UT El Paso).

\section{ACKNOWLEDGMENTS}

The authors thank all the contributing authors and reviewers for their efforts to make this special topic successful. We also thank the editorial staff at Frontiers in Ecology and Evolution for their invaluable assistance. 
Clutton-Brock, T. H., and Isvaran, K. (2006). Paternity loss in contrasting mammalian societies. Biol. Lett. 2, 513-516. doi: 10.1098/rsbl.2006.0531

Cohas, A., and Allaine, D. (2009). Social structure influences extra-pair paternity in socially monogamous mammals. Biol. Lett. 5, 313-316 doi: $10.1098 / \mathrm{rsbl} .2008 .0760$

Dawkins, R. (1980). "Good strategy or evolutionarily stable strategy," in Sociobiology: Beyond Naturel Nurture, eds G. W. Barlow and S. Silverberg (Boulder, CO: Westview Press), 331-367.

Dobson, F. S., Abebe, A., Correia, H. E., Kasumo, C., and Zinner, B. (2018). Multiple paternity and number of offspring in mammals. Proc. R. Soc. B Biol. Sci. 21, 1-7. doi: 10.1098/rspb.2018.2042

Dobson, F. S., Way, B. M., and Baudoin, C. (2010). Spatial dynamics and the evolution of social monogamy in mammals. Behav. Ecol. 21, 747-752. doi: 10.1093/beheco/arq048

Donaldson, Z. R., Spiegel, L., and Young, L. J. (2010). Central vasopressin V1a receptor activation is independently necessary for both partner preference formation and expression in socially monogamous male prairie voles. Behav. Neurosci. 124, 159-163. doi: 10.1037/a0018094

Emlen, S. T., and Oring, L. W. (1977). Ecology, sexual selection, and the evolution of mating systems. Science 197, 215-223. doi: 10.1126/science.327542

Fietz, J., Zischler, H., Schwiegk, C., Tomiuk, J., Dausmann, K. H., and Ganzhorn, J. U., (2000). High rates of extra-pair young in the pair-living fat-tailed dwarf lemur, Cheirogaleus medius. Behav. Ecol. Sociobiol. 49, 8-17. doi: 10.1007/s002650000269

Fischer, E. K., Nowicki, J. P., and O'Connell, L. A. (2019). Evolution of affiliation: patterns of convergence from genomes to behaviour. Philos. Trans. $R$ Soc. $B$ 374:20180242. doi: 10.1098/rstb.2018.0242

Gowaty, P. A., and Karlin, A. A. (1984). Multiple maternity and paternity in single broods of apparently monogamous eastern bluebirds (Sialia sialis). Behav. Ecol. Sociobiol. 15, 91-95. doi: 10.1007/BF00299374

Hames, R. (1996). Costs and benefits of monogamy and polygyny for Yanomamö women. Ethol. Sociobiol. 17, 181-199. doi: 10.1016/0162-3095(96)00003-9

Hiura, L. C., Kelly, A. M., and Ophir, A. G. (2018). Age-specific and contextspecific responses of the medial extended amygdala in the developing prairie vole. Dev. Neurobiol. 78, 1231-1245. doi: 10.1002/dneu.22648

Hiura, L. C., and Ophir, A. G. (2018). Interactions of sex and early life social experiences and sex at two developmengtal stages shape nonapeptide receptor profiles. Integr Zool. 13, 745-760. doi: 10.1111/1749-4877. 12338

Huck, M., Fernandez-Duque, E., Babb, P., and Schurr, T. (2014). Correlates of genetic monogamy in socially monogamous mammals: insights from Azara's owl monkeys. Proc. R. Soc. B Biol. Sci. 281:20140195. doi: 10.1098/rspb.2014.0195

Kappeler, P. M., and von Schaik, C. P. (2002). Evolution of primate social systems. Int. J. Primatol. 23, 707-740. doi: 10.1023/A:1015520830318

Kelly, A. M., Hiura, L. C., and Ophir, A. G. (2018). Rapid nonapeptide synthesis during a critical period of development in the prairie vole: plasticity of the paraventricular nucleus of the hypothalamus. Brain Struct. Funct. 223, 2547-2560. doi: 10.1007/s00429-018-1640-2

Klatt, J. D., and Goodson, J. L. (2013). Oxytocin-like receptors mediate pair bonding in a socially monogamous songbird. Proc. R. Soc. B 280:20122396. doi: $10.1098 / \mathrm{rspb} .2012 .2396$

Kleiman, D. G. (1977). Monogamy in mammals. Q. Rev. Biol. 52, 39-69. doi: $10.1086 / 409721$

Koprowski, J. L. (1993). Behavioral tactics, dominance and copulatory success among male fox squirrels. Ethol. Ecol. Evol. 5, 169-176. doi: 10.1080/08927014.1993.9523100

Lambert, C. (2018). ER $\alpha$ expression and monogamy in prairie voles: An experimental field study (Master's thesis). Miami University, Oxford, $\mathrm{OH}$, United States.
Lukas, D., and Clutton-Brock, T. H. (2013). The evolution of social monogamy in mammals. Science 341, 526-530. doi: 10.1126/science.1238677

Mock, D. W., and Fujioka, M. (1990). Monogamy and long-term pair bonding in vertebrates. TREE 5, 39-43. doi: 10.1016/0169-5347(90)90045-F

Ophir, A. G. (2017). Navigating monogamy: nonapeptide sensitivity in a memory neural circuit may shape social behavior and mating decisions. Front. Neurosci. 11:397. doi: 10.3389/fnins.2017.00397

Ophir, A. G., Wolff, J. O., and Phelps, S. M. (2008). Variation in neural V1aR predicts sexual fidelity and space use among prairie voles in semi-natural settings. Proc. Natl. Acad. Sci. U.S.A. 105, 1249-1254. doi: 10.1073/pnas.0709116105

Prounis, G. S., Foley, L., Rehman, A., and Ophir, A. G. (2015). Perinatal and juvenile social environments interact to shape cognitive behavior and neural phenotype in prairie voles. Proc. R. Soc. B 282:20152236. doi: $10.1098 / \mathrm{rspb} .2015 .2236$

Prounis, G. S., Thomas, K., and Ophir, A. G. (2018). Developmental trajectories and influences of environmental complexity on oxytocin receptor and vasopressin 1a receptor expression in male and female prairie voles. J. Comp. Neurol. 526, 1820-1842. doi: 10.1002/cne.24450

Reavis, R. H., and Barlow, G. W. (1998). Why is the coral-reef fish Valenciennea strigata (Gobiidae) monogamous? Behav. Ecol. Sociobiol. 43, 229-237. doi: $10.1007 / \mathrm{s} 002650050487$

Solomon, N. G., and Jacquot, J. J. (2002). Characteristics of resident and wandering prairie voles, Microtus ochrogaster. Can. J. Zool. 80, 951-955. doi: 10.1139/z02-053

Taborsky, M., Oliveira, R., and Brockmann, H. J. (2008). "The question of alternative reproductive tactics: concepts and questions," in Alternative Reproductive Tactics: An Integrative Approach, eds R. F. Oliviera, M. Taborsky, and H. J. Brockmann (Cambridge, Cambridge University Press), 1-22. doi: $10.1017 / \mathrm{CBO} 9780511542602$

Tinbergen, N. (1963). On aims and methods of ethology. Z für Tierpsychol. 20, 410-433. doi: 10.1111/j.1439-0310.1963.tb01161.x

van Schaik, C. P., and Dunbar, D. I. M. (1990). The evolution of monogamy in large primates: a new hypothesis and some crucial tests. Behaviour 115, 30-62. doi: 10.1163/156853990X00284

Westneat, D. F. (1987). Extra-pair fertilizations in a predominantly monogamous bird: genetic evidence. Anim. Behav. 35, 877-886. doi: 10.1016/S0003-3472(87)80123-9

Whiteman, E. A., and Côté, I. M. (2004). Monogamy in marine fishes. Biol Rev. 79, 351-375. doi: 10.1017/S1464793103006304

Williams, J. R., Catania, K. C., and Carter, C. S. (1992). Development of partner preferences in female prairie voles (Microtus ochrogaster): the role of social and sexual experience. Horm. Behav. 26, 339-349. doi: 10.1016/0018-506X(92)90004-F

Wittenberger, J. F., and Tilson, R. L. (1980). The evolution of monogamy: hypotheses and evidence. Ann. Rev. Ecol. Syst. 11, 197-232. doi: 10.1146/annurev.es.11.110180.001213

Young, L. J., and Wang, Z. (2004). The neurobiology of pair bonding. Nat. Neurosci. 7, 1048-1054. doi: 10.1038/nn1327

Conflict of Interest: The authors declare that the research was conducted in the absence of any commercial or financial relationships that could be construed as a potential conflict of interest.

Copyright (c) 2020 Solomon and Ophir. This is an open-access article distributed under the terms of the Creative Commons Attribution License (CC BY). The use, distribution or reproduction in other forums is permitted, provided the original author(s) and the copyright owner(s) are credited and that the original publication in this journal is cited, in accordance with accepted academic practice. No use, distribution or reproduction is permitted which does not comply with these terms. 